\title{
Cumulative Light Effects on Growth and Flowering of Tomato Seedlings
}

\author{
R.J. McAvoy ${ }^{1}$ and H.W. Janes \\ Department of Horticulture and Forestry, Cook College, Rutgers University, New Brunswick, \\ NJ 08903
}

\begin{abstract}
Additional index words. Lycopersicon esculentum, photosynthetic photon flux, PPF
Abstract. Tomato seedlings (Lycopersicon esculentum Mill. cv. Laura) were grown in an environmental chamber. In two separate experiments, plant growth from emergence to anthesis was divided into three equivalent segments based on either the actual number of days or the stage of plant development. In both experiments, plants were exposed to a high PPF $\left.\left(300 \mu \mathrm{mol} \cdot \mathrm{s}^{-1} \cdot \mathrm{m}^{-2}\right)^{2}\right)$ treatment $(\mathrm{H})$ for one segment and a lower PPF $\left(150 \mu \mathrm{mol} \cdot \mathrm{s}^{-1} \cdot \mathrm{m}^{-2}\right)$ treatment $(\mathrm{L})$, for the other two segments, resulting in three light treatment combinations (i.e., HLL, LHL, and LLH). Total dry weight and dry weight per unit of leaf area increased significantly in response to high PPF during all three treatment periods. Final plant weights and plant heights differed significantly between treatments, resulting in distinct plant growth characteristics. Plants from the HLL treatment began to flower 1 day before the LHL treatment and 2 days before the LLH treatment. The HLL plants initiated fewer leaves before initiation of the floral axis than the LHL and LLH plants. The light environment following the initial segment of seedling development most influenced final truss position at anthesis.
\end{abstract}

Some plant species appear to be relatively good integrators of both temperature and light over $24 \mathrm{hr}$ (Langhans et al., 1981; White and Warrington, 1988). The yield and growth of tomato does not fluctuate significantly within a given daily temperature integral (DTI), regardless of the daily temperature pattern used to achieve this DTI (Hurd and Graves, 1984). Flowering of the tomato, node number, and time from emergence to flower appearance also varies little within a given daily light integral (DLI) (Kinet, 1977). However, plant response to a cumulative light integral applied unequally over a period spanning different stages of vegetative and/or reproductive development is less predictable than is plant response to a DLI (Erickson et al., 1980; Schapendonk et al., 1984).

Seasonal light and temperature differences during tomato seedling development influence both vegetative growth (Klapwijk, 1981; Klapwijk and de Lint, 1975) and flowering response (Calvert, 1959). Light influences flower initiation during early seedling development and flower development and expression in the later stages of seedling development (Calvert, 1969; Kinet, 1977). Klapwijk and Wubben (1984) reported that plants exposed to high light and low temperatures during truss initiation produced fewer leaves below the first truss as opposed to the high temperature/low light treatment; however, earliness of the first flower truss was offset by an increased number of leaves between truss numbers 1 and 2 .

The position of the inflorescence at anthesis is influenced by lateral shoot development (Pickens et al., 1985). As indeterminate tomato seedlings develop, initiation of the floral axis terminates the primary vegetative axis (Sawhney and Greyson, 1972) and strong vegetative growth resumes from the axils of the last two initiated leaves on the primary sympodium, directly below the inflorescence (Aung, 1976). The shoot originating from the axil of the last initiated leaf displaces the inflorescence

Received for publication 15 Aug. 1988. New Jersey Agricultural Experiment Station Publication no. D-03130-29-88. This project was performed as a part of NJAES Project no. 03130, supported by the NJAES, Hatch Act funds. The mention of commercial names does not represent and endorsement of a product or company. The cost of publishing this paper was defrayed in part by the payment of page charges. Under postal regulations, this paper therefore must be hereby marked advertisement solely to indicate this fact.

'Present address: Dept. of Plant Science, Univ. of Connecticut, Storrs, CT 06269-4067. into a lateral position as it develops. Simultaneously, the last initiated leaf is also displaced by the development of the lateral shoot so that, at anthesis, the inflorescence appears in the internode between the last two initiated leaves on the primary sympodium (Calvert, 1965; Pickens et al., 1985).

In this study, experiments were designed to investigate how the vegetative and reproductive characteristics of tomato seedlings respond to cumulative light integrals (CLI) applied unequally during seedling development.

\section{Materials and Methods}

Osmotically primed 'Laura' tomato seeds (an indeterminate cultivar) were sown directly into standard round 1.8 -liter pots containing a 2 peat : 2 vermiculite : 1 perlite mix (by volume), amended with (all in $\mathrm{kg}-\mathrm{m}^{-3}$ ) 4.82 dolomitic lime, 1.06 super phosphate (20\%), $0.6 \mathrm{KNO}_{3}, 0.6 \mathrm{MgSO}_{4}, 1.65$ gypsum, 0.053 fritted trace elements, $0.026 \mathrm{~B}$, and $0.04 \mathrm{Fe}$. The pots were watered, covered with damp brown paper, and placed in a dark chamber and maintained at a constant $24 \mathrm{C}$ until the seedlings began to emerge. The pots were then uncovered, lights were switched on and the temperature was lowered to 20C. Carbon dioxide was maintained, during light hours, at $500 \mu 1 \cdot$ liter $^{-1}$. Plants were fertilized with $200 \mathrm{mg}$ N/liter (15 N-6.6p-12.5K) with each watering.

The seedling developmental period from emergence to first anthesis was divided into three equal segments using either number of days or number of leaves, forming the basis of two separate experiments. Preliminary growth studies were used to determine treatment intervals.

In both experiments, plants were exposed to a high PPF treatment, (19.44 mol $\left.\cdot \mathrm{day}^{-1} \cdot \mathrm{m}^{-2} ; 300 \mu \mathrm{mol} \cdot \mathrm{s}^{-1} \cdot \mathrm{m}^{-2}\right)$, for one segment and a lower one $\left(9.72 \mathrm{~mol} \cdot \mathrm{day}^{-1} \cdot \mathrm{m}^{-2} \mathrm{PPF} ; 150\right.$ $\left.\mu \mathrm{mol} \cdot \mathrm{s}^{-1} \cdot \mathrm{m}^{-2}\right)$, for the other two segments. The light levels were maintained for $18 \mathrm{hr}$ daily ( 0400 to $220 \mathrm{HR}$ ). The three light treatment combinations were: 1) high PPF in the first segment (HLL), 2) high PPF in the second segment (LHL), and 3) high PPF in the third segment (LLH).

Number of days. Each light treatment segment was 11 days long. All three treatment groups had received the same CLI (428 mol. $\mathrm{m}^{2}$ ) upon completion of the experiment. The experiment was started on 26 Jan. and repeated, starting 13 Mar. and 23 July 1987. 
Number of leaves. Each stage of development was equivalent in respect to the number of leaves produced during the segment. Plants were transferred between light treatments when the terminal leaflet of the fifth, 10th, and 15 th leaf was $2.5 \mathrm{~cm}$ long. Since this criterion was based on the stage of plant development, and not chronological time, not all treatment combinations received equal PPF. The HLL treatment reached the fifth-leaf stage on day 14 and received a total of $455 \mathrm{~mol} \cdot \mathrm{m}^{-2}$ over the course of the experiment. The LHL treatment reached the fifthleaf stage on day 16 and received high PPF until the 10th leaf stage (day 23), with a CLI of $390 \mathrm{~mol} \cdot \mathrm{m}^{-2}$. The LLH treatment received high PPF from day 25 to 33 and received a CLI of 400 $\mathrm{mol} \cdot \mathrm{m}^{-2}$. The experiment was started on $22 \mathrm{Apr}$. 1987 and was repeated starting on 4 June 1987.

Thirty plants were subjected to each PPF treatment combination. Treatment plants were surrounded by a border row to alleviate edge effects. Lateral shoots that developed were not removed. Five plants were randomly selected and sampled from each PPF treatment on each of six sampling dates. After each sampling, the remaining plants were rearranged so that each plant received equal space within a treatment block. The statistical model was a completely randomized design. Analysis of variance procedures were used to analyze the data. Duncan's multiple range test was used to identify significant differences between treatment means.

Leaf area and fresh and dry weights of the leaves and stems were recorded along with plant height. Flowering was noted at the onset of anthesis (when the sepals began to part and the petals began to elongate) and again as the petals reflexed $90^{\circ}$ from their pre-expanded position. Both the number of flowers meeting these two criteria and the date of the occurrence were recorded.

Truss position was evaluated at the end of each experiment by recording both the number of leaves subtending the flowering truss, and the number of leaves below the vigorous lateral originating from the next to last initiated leaf on the primary sympodium, hereafter referred to as the secondary lateral shoot. Together, these data indicate changes in the relative position of the inflorescence as a result of lateral shoot development.

A single large $\left(20-\mathrm{m}^{2}\right)$ walk-in environmental chamber was used to house all three PPF treatment groups simultaneously. Light uniformity within each PPF treatment group was maintained by adjusting both the spacing of the high-pressure sodium light fixtures and the reflective panels in the chamber. A constant 20C air temperature was maintained during all experiments. PPF levels were constantly monitored at the canopy level with a LI-COR 190-SB quantum sensor located in each treatment block. As the plants grew the quantum sensors were raised.

\section{Results and Discussion}

\section{Vegetative growth and development}

Number of days. Vegetative growth and development differed significantly between PPF treatments (Table 1). Treatments that produced similar plant heights resulted in different final dry weights. The combination of these growth characteristics resulted in plants that were visibly different.

The total dry weight of the HLL plants were significantly greater than the LHL and LLH plants at the end of period one. The LHL plants attained the greatest total dry weight at the end of period two, statistically similar to the HLL plants. The LLH plants attained the greatest total dry weight at the end of the
Table 1. Influence of an 1 1-day high-low PPF sequence, applied differentially during seedling development, on vegetative growth.

\begin{tabular}{lcccr}
\hline \hline \multirow{2}{*}{$\begin{array}{l}\text { Growth } \\
\text { variable }\end{array}$} & Light & \multicolumn{3}{c}{ Sampling day and (period) } \\
\cline { 3 - 5 } treatment & $11(1)$ & $22(2)$ & $33(3)$ \\
\hline Total plant dry wt $(\mathrm{g})$ & HLL & $0.3 \mathrm{~b}$ & $3.5 \mathrm{~b}$ & $14 \mathrm{a}$ \\
& LHL & $0.1 \mathrm{a}$ & $4.5 \mathrm{~b}$ & $14 \mathrm{a}$ \\
& LLH & $0.1 \mathrm{a}$ & $2.3 \mathrm{a}$ & $19 \mathrm{~b}$ \\
Leaf area index & HLL & $0.32 \mathrm{~b}$ & $2.4 \mathrm{~b}$ & $3.0 \mathrm{a}$ \\
& LHL & $0.16 \mathrm{a}$ & $2.3 \mathrm{ab}$ & $3.0 \mathrm{a}$ \\
& LLH & $0.16 \mathrm{a}$ & $1.8 \mathrm{a}$ & $3.4 \mathrm{a}$ \\
Leaf area ratio $\left(\mathrm{cm}^{2} \cdot \mathrm{g}^{-1}\right)$ & HLL & $249 \mathrm{a}$ & $254 \mathrm{~b}$ & $195 \mathrm{~b}$ \\
& LHL & $356 \mathrm{~b}$ & $188 \mathrm{a}$ & $193 \mathrm{~b}$ \\
& LLH & $360 \mathrm{~b}$ & $298 \mathrm{~b}$ & $158 \mathrm{a}$ \\
Plant height $(\mathrm{cm})$ & HLL & $6 \mathrm{~b}$ & $33 \mathrm{~b}$ & $75 \mathrm{~b}$ \\
& LHL & $4 \mathrm{a}$ & $27 \mathrm{a}$ & $64 \mathrm{a}$ \\
& LLH & $4 \mathrm{a}$ & $29 \mathrm{ab}$ & $67 \mathrm{a}$ \\
\hline
\end{tabular}

${ }^{2}$ Each number is the mean of 15 plants.

${ }^{y}$ Data followed by different letters indicate significant differences between light treatments on a certain sampling date at $P=0.05$, Duncan's multiple range test.

Table 2. Influence of a high-low PPF sequence, applied at different leaf stages of tomato seedling development, on vegetative growth.

\begin{tabular}{lcccr}
\hline \hline \multirow{2}{*}{$\begin{array}{l}\text { Growth } \\
\text { variable }^{z}\end{array}$} & \multicolumn{3}{c}{$\begin{array}{c}\text { Stage of leaf development } \\
\text { at }\end{array}$} \\
\cline { 3 - 5 } sompling time & $\begin{array}{c}\text { Light } \\
\text { treatment }\end{array}$ & Fifth & 10 th & 15 th \\
\cline { 3 - 5 } & HLL & $0.7 \mathrm{~b}$ & $4.4 \mathrm{~b}$ & $15 \mathrm{a}$ \\
& LHL & $0.3 \mathrm{a}$ & $5.2 \mathrm{~b}$ & $13 \mathrm{a}$ \\
Leaf area index & LLH & $0.3 \mathrm{a}$ & $3.0 \mathrm{a}$ & $20 \mathrm{~b}$ \\
& HLL & $0.8 \mathrm{~b}$ & $2.2 \mathrm{a}$ & $3.4 \mathrm{a}$ \\
& LHL & $0.5 \mathrm{a}$ & $2.1 \mathrm{a}$ & $3.1 \mathrm{a}$ \\
Leaf area ratio $\left(\mathrm{cm}^{2} \cdot \mathrm{g}^{-1}\right)$ & LLH & $0.4 \mathrm{a}$ & $1.8 \mathrm{a}$ & $3.5 \mathrm{a}$ \\
& HLL & $261 \mathrm{a}$ & $220 \mathrm{ab}$ & $213 \mathrm{~b}$ \\
& LHL & $351 \mathrm{~b}$ & $184 \mathrm{a}$ & $220 \mathrm{~b}$ \\
Plant height $(\mathrm{cm})$ & LLH & $343 \mathrm{~b}$ & $262 \mathrm{~b}$ & $161 \mathrm{a}$ \\
& HLL & $12 \mathrm{~b}$ & $34 \mathrm{~b}$ & $72 \mathrm{~b}$ \\
& LHL & $9 \mathrm{a}$ & $29 \mathrm{a}$ & $60 \mathrm{a}$ \\
& LLH & $9 \mathrm{a}$ & $32 \mathrm{ab}$ & $63 \mathrm{a}$ \\
\hline
\end{tabular}

${ }^{2}$ Each number is the mean of 10 plants.

${ }^{y}$ Data followed by different letters indicate significant differences between light treatments on a certain sampling date at $P=0.05$, Duncan's multiple range test.

study. The final height of the HLL plants were significantly greater than either the LHL or the LLH plants.

Leaf area index (LAI; leaf area per unit of ground area) differed significantly early in seedling development (Table 1). The HLL plants produced more canopy than either the LHL and LLH plants after the first 11 days, greatly enhancing the light interception capability of these plants. As a result, the HLL plants accumulated more total dry weight (3.21 g) during days 11 to 22 than the LLH plants $(2.20 \mathrm{~g})$, while exposed to the same total PPF. The change in the leaf area ratio (LAR), i.e., total leaf area per total plant dry weight, was very rapid, with differences noted 6 days after the start of the experiment. In response to the high $\mathrm{PPF}$, large plants with thick leaves were produced.

Number of leaves. The HLL plants accumulated significantly more total dry weight than the others until the fifth leaf stage 
Table 3. Influence of an 1 1-day high-low PPF sequence, applied differentially during seedling development, on flowering and truss position.

\begin{tabular}{|c|c|c|c|c|c|}
\hline \multirow{2}{*}{$\begin{array}{l}\text { Truss } \\
\text { expression } \\
\text { variable }\end{array}$} & \multirow{2}{*}{$\begin{array}{l}\text { Light } \\
\text { treatment }\end{array}$} & \multicolumn{4}{|c|}{ Sampling day $^{\text {zy }}$} \\
\hline & & 30 & 31 & 32 & 33 \\
\hline \multirow[t]{3}{*}{ Flowers with petals reflexed } & HLL & $0.2 \mathrm{a}$ & $0.6 \mathrm{~b}$ & $0.9 \mathrm{~b}$ & $1.6 \mathrm{a}$ \\
\hline & LHL & $0.0 \mathrm{a}$ & $0.3 \mathrm{ab}$ & $0.7 \mathrm{~b}$ & $1.6 \mathrm{a}$ \\
\hline & LLH & $0.0 \mathrm{a}$ & $0.0 \mathrm{a}$ & $0.1 \mathrm{a}$ & $0.9 \mathrm{a}$ \\
\hline \multirow[t]{3}{*}{ Flowers with petals elongating } & HLL & $0.8 \mathrm{~b}$ & $1.3 \mathrm{~b}$ & $1.7 \mathrm{a}$ & $2.5 \mathrm{a}$ \\
\hline & LHL & $0.8 \mathrm{~b}$ & $1.6 b$ & $1.8 \mathrm{a}$ & $2.3 \mathrm{a}$ \\
\hline & LLH & $0.0 \mathrm{a}$ & $0.0 \mathrm{a}$ & $1.0 \mathrm{a}$ & $1.9 \mathrm{a}$ \\
\hline \multirow[t]{3}{*}{ Leaves below secondary lateral shoot } & HLL & & & & $8.6 \mathrm{a}$ \\
\hline & LHL & & & & $9.3 \mathrm{~b}$ \\
\hline & LLH & & & & $9.4 \mathrm{~b}$ \\
\hline \multirow[t]{3}{*}{ Leaves below the flower truss } & HLL & & & & $9.5 \mathrm{a}^{* * * *}$ \\
\hline & LHL & & & & $9.5 \mathrm{a}^{\mathrm{NS}}$ \\
\hline & LLH & & & & $10.2 b^{* * *}$ \\
\hline
\end{tabular}

${ }^{z}$ Each number is the mean of 15 plants.

'Data followed by different letters indicate significant differences between light treatments on a certain sampling date at $P=0.05$, Duncan's multiple range test.

$* * * * * * *$ Differences between the plant responses "leaves below the secondary lateral shoot" and "leaves below the flower truss" within each light treatment group using one-way ANOVA F-test at $P=0.001$ and 0.0001 , respectively. NS $=$ nonsignificance.

Table 4. Influence of a high-low PPF sequence, applied at different leaf stages of tomato seedling development, on flowering and truss position.

\begin{tabular}{|c|c|c|c|c|c|}
\hline \multirow{2}{*}{$\begin{array}{l}\text { Truss } \\
\text { expression } \\
\text { variable }\end{array}$} & \multirow{2}{*}{$\begin{array}{c}\text { Light } \\
\text { treatment }\end{array}$} & \multicolumn{4}{|c|}{ Sampling day $^{2 y}$} \\
\hline & & 30 & 31 & 32 & 33 \\
\hline Flowers with petals reflexed & $\begin{array}{l}\text { HLL } \\
\text { LHL } \\
\text { LLH }\end{array}$ & $\begin{array}{ll}0.0 & \mathrm{a} \\
0.0 & \mathrm{a} \\
0.0 & \mathrm{a}\end{array}$ & $\begin{array}{l}0.6 \text { a } \\
0.0 \\
0.0\end{array}$ & $\begin{array}{l}1.0 \mathrm{~b} \\
0.2 \mathrm{ab} \\
0.0 \mathrm{a}\end{array}$ & $\begin{array}{l}1.6 \mathrm{~b} \\
0.7 \mathrm{a} \\
0.9 \mathrm{a}\end{array}$ \\
\hline Flowers with petals elongating & $\begin{array}{l}\text { HLL } \\
\text { LHL } \\
\text { LLH }\end{array}$ & $\begin{array}{ll}0.6 & \mathrm{a} \\
0.0 & \mathrm{a} \\
0.0 & \mathrm{a}\end{array}$ & $\begin{array}{ll}0.8 & \mathrm{a} \\
0.4 & \mathrm{a} \\
0.0 & \mathrm{a}\end{array}$ & $\begin{array}{l}1.7 \mathrm{~b} \\
1.2 \mathrm{ab} \\
0.8 \mathrm{a}\end{array}$ & $\begin{array}{l}2.5 \mathrm{a} \\
2.1 \mathrm{a} \\
1.8 \mathrm{a}\end{array}$ \\
\hline Leaves below secondary lateral shoot & $\begin{array}{l}\text { HLL } \\
\text { LHL } \\
\text { LLH }\end{array}$ & & & & $\begin{array}{l}8.5 \mathrm{a} \\
9.3 \mathrm{~b} \\
9.1 \mathrm{~b}\end{array}$ \\
\hline Leaves below the flower truss & $\begin{array}{l}\text { HLL } \\
\text { LHL } \\
\text { LLH }\end{array}$ & & & & $\begin{array}{c}9.1 \mathrm{a}^{*} \\
9.8 \mathrm{~b}^{\mathrm{NS}} \\
10.0 \mathrm{~b}^{* *}\end{array}$ \\
\hline
\end{tabular}

${ }^{2}$ Each number is the mean of 10 plants.

${ }^{y}$ Data followed by different letters indicate significant differences between light treatments on a certain sampling date at $P=0.05$, Duncan's multiple range test.

***Differences between the plant responses "leaves below the secondary lateral shoot" and "leaves below the flower truss" within each light treatment group using one-way ANOVA Ftest at $P=0.05$ and 0.01 , respectively. NS $=$ nonsignificance.

of development had been reached (Table 2). The plants receiving the high PPF during the fifth to 10th leaf stage (LHL), attained the greatest total dry weight at the end of period two. The LLH plants attained a significantly greater total dry weight at the end of the experiment than the LHL plants, even though both treatments received a similar CLI.

In both experiments, the vegetative growth response depended on how the CLI was applied during the growth cycle. Emerging seedlings developed a canopy fastest in the high PPF environment (HLL), enabling these plants to intercept light more effectively. The absolute size of the plant at the end of the first segment indicated that there was very little carbohydrate stored for subsequent growth. Since assimilate stored in leaves for periods exceeding $24 \mathrm{hr}$ is typically not remobilized (Ho, 1979), subsequent changes in the vegetative response can be attributed to the prevailing PPF environment, as reflected in the rapidly changing LAR (Hurd and Thornley, 1974).

\section{Flowering}

Number of days. Flowering responses differed significantly between PPF treatments (Table 3). Flowers on the HLL plants began to display reflexed petals 1 day before the LHL plants and 2 days before the LLH plants. Relative position of the 
inflorescence was also affected by the timing of the high-PPF treatment (Table 3). Fewer leaves had been initiated below the secondary lateral shoot of the HLL plants by day 33 than were initiated below this shoot on both the LHL and LLH plants. However, both the HLL and LHL plants produced an equal number of leaves below the flower truss. These data indicate that the floral axis was initiated during the first 11 days of seedling development and that the PPF environment following initiation of the floral axis influenced the position of the flowering truss relative to the secondary lateral shoot at anthesis. In our study, plants exposed to low PPF during days 11 to 22 (HLL and LLH) did not express the inflorescence between the last two initiated leaves on the primary sympodium, as typically occurs (Pickens et al., 1985), but expressed it above the last initiated leaf on the primary sympodium. As a result, significantly more leaves were observed below the flower truss (day 33) for both the HLL and LLH plants than were observed below the secondary lateral shoot for these two treatment groups. The LHL plants received high PPF during days 11 to 22 and produced a similar number of leaves below both the flower truss and the secondary lateral shoot; thus, the in florescence was expressed between the last two initiated leaves on the primary sympodium.

Number of leaves. Plants from the HLL treatment began to display petal elongation and reflection 1 day before the LHL plants and 2 days before the LLH plants (Table 4). The LHL and LLH plants were most similar with respect to the timing of anthesis and received a similar CLI over the course of the experiment. During the 33 days, the HLL plants initiated fewer leaves below the secondary lateral shoot than the LHL and LLH plants, which were similar. Plants from the HLL and LLH treatments produced significantly more leaves below the flowering truss than were produced below the secondary lateral shoot.

In our study, floral initiation was only one factor contributing to the earliness of anthesis. In general, the HLL plants began to flower first, followed by the LHL plants and then the LLH plants. Since LHL and the LLH plants produced an equal number of leaves below the floral axis, differences in the timing of anthesis occurred after floral initiation. The LHL plants, in the equal number of days experiment, were similar to the HLL plants with respect to petal reflection (day 32) and leaves below the flower truss (Table 3). However, in the number of leaves experiment, the LHL plants received high PPF during days 16 to 23 , a time interval chronologically more distant from the period of floral initiation. These plants reflexed petals at the same time as the LLH plants and displayed a similar number of leaves below the flower truss (day 33).

A record of the actual time required to achieve a specific growth stage under both high and low PPF indicated that the greatest effect of PPF on the rate of leaf development occurred soon after plant emergence. Emerging seedlings exposed to a high PPF (HLL) reached the fifth leaf stage in 14 days, while those exposed to a low PPF (LHL and LLH) required 16 days; thus, there resulted a 2-day difference very early in seedling development. Plants required 7 days of exposure in high PPF (LHL) to develop from the fifth to the 10th leaf stage, while plants receiving low PPF (LLH) required 9 days to reach the 10th leaf stage of development, the same 2-day delay. The final appearance of plants from the three treatment groups differed more than the 2-day delay may suggest. The LHL plants developed significantly different vegetative growth characteristics at the 10th leaf stage of development than the LLH plants that received low PPF during the fifth to 10th leaf stage of development (Table 2).

Kinet (1977) reported that the DLI influenced the node of flower initiation and the number of days to initial anthesis. A high DLI reduced the time to initial anthesis and fewer leaves were initiated below the first truss. The light intensity and daily photosynthetic duration were not important, provided that the DLI was the same, indicating good daily light integration. The data obtained in our study indicate that light integration was poor when the CLI was provided unequally over different segments of seedling development, resulting in dissimilar vegetative and flowering characteristics.

\section{Literature Cited}

Aung, L.H. 1976. Influence of certain plant factors on the growth and flowering of the lower axillary shoot of Lycopersicon esculentum Mill. Ann. Bet. (London) 40:723-729.

Calvert, A. 1959. Effect of the early environment on the development of flowering in tomato: 11. Light and temperature interactions. J. Hort. Sci. 34:154-162.

Calvert, A. 1965. Flower initiation and development in the tomato. N.A.A.S.Q. Rev. 70:79-88.

Calvert, A. 1969. Studies on the post-initiation development of flower buds of tomato (Lycopersicon esculentum). J. Hort. Sci. 44:117126.

Erickson, V. L., A. Armitage, W.H. Carlson, and R.M. Miranda. 1980. The effect of cumulative photosynthetically active radiation on the growth and flowering of the seedling geranium, Pelargonium $\times$ hortorum Bailey. HortScience 15(5):815-817.

Ho, L.C. 1976. The relationship between the rates of carbon transport and of photosynthesis in tomato leaves. J. Expt. Bet. 27(96):87-97.

Ho, L.C. 1979. Regulation of assimilate translocation between leaves and roots in the tomato. Ann. Bet. 43:437-448.

Hurd, R.G. and C.J. Graves. 1984. The influence of different temperature patterns having the same integral on the earliness and yield of tomatoes. Acta Hort. 148:547-554.

Hurd, R.G. and J.H.M. Thornley. 1974. An analysis of the growth of young tomato plants in water culture at different light integrals and CO, concentrations I. Physiological aspects. Ann. Bet. 38:375-388.

Kinet, J.M. 1977. Effect of light conditions on the development of the inflorescence in tomato. Scientia Hort. 6: 15-26.

Klapwijk, D. 1981. Effect of season on early tomato growth and development rates. Neth. J. Agr. Sci. 29: 179-188.

Klapwijk, D. and P.J.A.L. de Lint 1975. Growth rates of tomato seedlings and seasonal radiation. Neth. J. Agr. Sci. 23:259-268.

Klapwijk, D. and C.F.M. Wubben. 1984. Light, temperature and the first three inflorescences in greenhouse tomatoes. Acts Hort. 148:925931.

Langhans, R. W., M. Wolfe, and L.D. Albright. 1981. Use of average night temperatures for plant growth for potential energy savings. Acta Hort. 115:31-37.

Pickens, A. J. F., R.G. Hurd, and D. Vince-Prue. 1985. Lycopersicon esculentum, p. 330-346. In: A.H. Halevy (cd.). CRC handbook of flowering. CRC Press, Boca Raton, Fl.

Sawhney, V.K. and R.I. Greyson. 1972. On the initiation of the inflorescence and floral organs in tomato (Lycopersicon esculentum). Can. J. Bet. 50:1493-1495.

Schapendonk, A. H. C. M., H. Challa, P.W. Broekharst, and A.J. Udink Ten Cate. 1984. Dynamic climate control; an optimization study for earliness of cucumber production. Scientia Hort. 23: 137-150.

White, J.W. and I.J. Warrington. 1988. Temperature and light integral effects on growth and development of hybrid geraniums. J. Amer. Soc. Hort. Sci. 113(3):354-359. 